
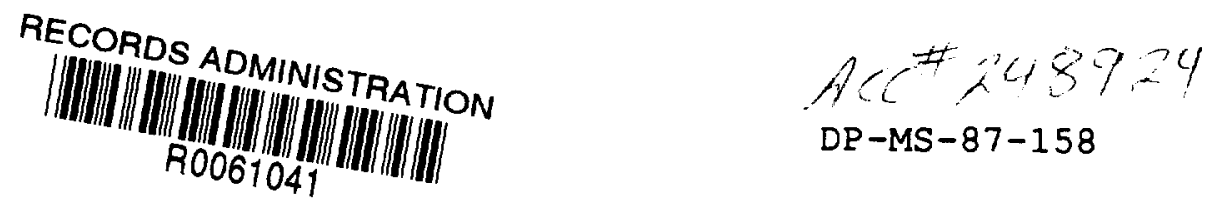

\title{
PREDICTION OF GLASS DURABILITY AS A FUNCTION OF ENVIRONDENTAI CONDITIONS
}

by

C. M. Jantzen

E. I. du Pont de Nemours \& Co. Savannah River Laboratory Aiken, SC 29808

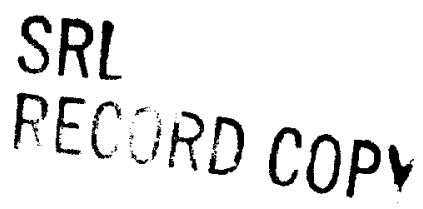

An invited keynote review paper proposed for presentation at The Symposium on Materials Stability and Environmental Degradation, Materials Research Society Spring Meeting, Reno, Nevada April 5-9, 1988

and for publication in the proceedings

This paper was prepared in connection with work done under Contract No. DE-AC09-76SR00001 with the U.S. Department of Energy. By acceptance of this paper, the publisher and /or recipient acknowledges the U.S. Government's right to retain a nonexclusive, royalty-free license in and to any copyright covering this paper, along with the right to reproduce and to authorize others to reproduce all or part of the copyrighted paper. 


\section{PREDICTION OF GLASS DURABMITY AS A FUNCTION OF ENVIRONMENTAI CONDITIONS}

C. M. Jantzen

E. I. du Pont de Nemours \& Co.

Savannah River Laboratory

Alken, SC 29808

\section{ABSTRACT}

A thermodymamic model of glass durabillty has been applied to natural, ancient. and nuclear waste glasses. The durabllities of over 150 different natural and man-made glasses. including actual ancient Roman and Islamic glasses (Jalame ca. 350 A. D., Nishapur 10-1 1th century A. D.. and Gorgon 9-11th century A.D.), have been compared. Glass durabllity has been shown to be a function of the thermodynamic hydration free energy. $\Delta \mathrm{G}_{\text {hyd. }}$ which can be calculated from glass composition and solution pH. Using this approach the durabllity of the most durable nuclear waste glasses examined was $-10^{6}$ years by comparison with the durabillty of the natural basalts of $\sim 10^{6}$ years. The least durable waste glass formulations were comparable in durability to the most durable simulated medteval window glasses of $-10^{3}$ years. In this manner. the durability of nuclear waste glasses has been interpolated to be $\sim 10^{6}$ years and no less than $10^{3}$ years.

Hydration thermodynamics have been shown to be applicable to the dissolution of glass in various natural environments. Groundwater-glass interactions relative to geologic disposal of nuclear waste, hydration rind dating of obsidians, and or other archeological studies can be modeled. e.g. the relative durabilities of six simulated medieval window glasses have been correctly predicted for both laboratory (one month) and burial (5 year) experiments.

The effects of solution $\mathrm{pH}$ on glass dissolution has been determined expertmentally for the 150 different glasses and can be predicted theoretically by hydration thermodynamics. The effects of solution redox (oxddation potential expressed as Eh) on dissolution of glass matrix elements such as SI and B have been shown to be minimal. The combined effects of solution $\mathrm{pH}$ and Eh have been described and unifled by construction of thermodynamically calculated Pourbaix ( $\mathrm{PH}-\mathrm{Eh}$ ) diagrams for glass dissolution. The Pourbaix diagrams have been quantifed to describe glass dissolution as a function of environmental conditions by use of the data dertved from hydration thermodynamics.

\section{INTRODUCTION}

The durabllity of a glass is a function of both kinetic and thermodynamic stability in an aqueous environment $[1,2]$. Kinetic models have been applied to the time dependent corrosion of glasses [3-6]. waste glasses $[7,8]$, and crystalline sillcates $[5,9]$. These models mathematically describe ion exchange. diffuston. and protective layer formation in the form of time dependent master equations. Kinetic models describe the leaching behavior of a glven glass but they do not predict which of a gtven group of glasses will be most durable. 
Chemical thermodynamics has also been used to predict the stabllity of vitreous $[1-2,10-11]$ and crystalline silicates $[11-14]$ in aqueous environments. Application of chemical thermodynamics does not require determination of the time dependent kinetics of the leaching processes, but does compare the thermodynamic stability of the reactants (glass or crystalline silicates in solution) to the product species formed during leaching or weathering, e.g. sillcic acid, cations or complexes in solution. precipitates. and /or sollds. Such an ontological approach to glass durability was formulated by Newton and Paul [15] and applied to (1) the weathering of medieval window glasses and (2) to a comparison of the relative stabilities of these glasses to Roman window glass, modern container glass, pyrex laboratory ware, and natural flint glass. A logarithmic relationship was found between a hydration free energy, which was calculated from glass composition, and such measures of reaction progress as $\mathrm{K}_{2} \mathrm{O}$ released from the glass and "loss of thickness" of the glass measured in mm/century.

Determination of glass durability as a function of glass composition [15] is significant to the development of durable commercial glasses to be used as containers for corrosive liquids, to the understanding of the effects of dishwasher detergents on glass durabillty, to the understanding of the weathering of medleval and modern window glasses, and to the development of durable glasses for nuclear waste disposal. The long radioactive half-lives of fission products and actinides in high-level nuclear wastes require that they be isolated from the blosphere for $10^{3}$ to $10^{5}$ years. The isolation technique selected [16] for defense high-level waste produced at the Savannah River Plant is immobilization in borosilicate glass and subsequent emplacement in a geologic repository. The intruston of groundwater into and passage through a repository, is the most likely mechanism by which radionuclides may be removed from the waste glass and cartied to the blosphere. Thus, it is important that nuclear waste glasses be stable in the presence of groundwaters for very long pertods of time.

It is impossible to directly demonstrate the long-term stabllity of any nuclear waste form. However, the existence of natural glasses, such as obsidians, basalts, or tektttes, which are millions of years old, demonstrates that glasses can be formulated which will survive geologic environments. Similarly, synthetic glasses of known longevity or performance, such as medieval window glasses, can also demonstrate the potential long-range performance of nuclear waste glass. The concept of using natural glasses as analogues for waste glass durabllity was first proposed by Ewing [17]. Subsequent laboratory comparisons of the durability of rhyolite glasses [18] and basaltic glasses [19] to French. United Kingdom, and German nuclear waste glasses demonstrated that waste glasses can be fabricated to be as durable as some natural glasses. These mechanistic studies did not, however, provide a basis for predicting the glass composittons for which this would be true.

To quantify the relative durabilities of nuclear waste glasses their performance relative to natural and ancient glasses (whose long-term performance is known) was investigated [20-25]. The thermodynamic approach of Newton and Paul [15] was applied to over 300 experimental laboratory results. Although equilibrium is rarely achieved in short term laboratory tests, the use of equilibrium thermodynamics furnishes a quantitative frame of reference for the relationship between any solid species and aqueous environments on histortc and geologic time scales. During these studies, the thermodynamic approach of Newton and Paul [15] was expanded and shown to be applicable to a wide variety of glasses [20-25] In vartous environmental conditions [26]. Jantzen [24-25] combined the thermodynamic approach for glass durability with the thermodynamic approach used by Pourbalx [11] and Garrels [12] to describe the effects of natural aqueous environments on metallurgical and mineralogic species. Jantzen's construction of Pourbaix diagrams for glass dissolution has conceptually and quantattvely unifled the dissolution behavior of all glasses as a function of the $\mathrm{pH}-\mathrm{Eh}$ conditions imposed in natural environments. The results of these studies will be reviewed. 


\section{Glass Durabulity: A Function of Glass Composition}

The thermodynamic approach of Newton and Paul [15] assumes that the glass is a mechanical mixture of orthosilicate and oxide components. The overall free energy of hydration of a glass is assumed to be an additive function of the free energies of the hydration reactions of the individual sillcate and oxdde components. The formalism is

$$
\Delta G_{\text {hyd }}=\Sigma x_{1} \cdot\left(\Delta G_{\text {hyd }}\right)_{1}
$$

where $\left(\Delta G_{\text {hyd }}\right)_{1}$ is the free energy change of the thermodynamically most stable hydration reaction of component 1 at mole fraction $x_{1}$.

Newton and Paul [15] did not apply their approach to borosilicate glasses. In order to evaluate borostllcate based nuclear waste glasses. Plodinec and Jantzen $[20,21]$ chose a consistent set of hydration reactions which included a reaction for borlc oxide hydrating to boric acid. The thermodynamic data base of Paul [2] and Garrels and Christ [12] was used as the thermodynamic input for the hydration reactions. If a stable hydration product was observed experimentally on a leached glass surface (the hydration reaction for this product usually had a higher free energy of formation than the theoretical $\left.\left(\Delta G_{\text {hyd }}\right)_{1}\right)$, the free energy of formation for the observed hydration product, ( $\Delta G_{\text {hyd }}$ obs, was preferentially used [23).

Linear relationships were determined between the logarithmic extent of hydration (log NLSi released from the glass in grams of glass per square meter of glass surface area) and the calculated $\Delta G_{h y d}$ for over 300 glass dissolution experiments in delonized water [23]. The thermodynamic approach [15, 20-21], assumed that the sllicate and borate components of a glass hydrated to silicic acid and boric acid respectively. For poorly durable glasses where the alkall released from the glass drove the solution $\mathrm{pH}$ to greater than 9.5, the logarithmic function of reaction progress verses $\Delta \mathrm{G}_{\text {hyd }}$ was not accurate $[22-23]$. At $\mathrm{pH}$ values of $>9.5$, the solubility of silica and borate increases rapidly due to dissociation of silicic acid. Jantzen [22-23] demonstrated that an additional contribution to the hydration free energy based on the dissociation constants of silictc and boric acld at high $\mathrm{pH}$ was necessary. To account for the dissoctation of sillicic and boric acid at high $\mathrm{pH}$, the equations below are calculated as additional contributions to $\Delta \mathrm{G}_{\text {hyd: }}$

for $\mathrm{H}_{2} \mathrm{SiO}_{3}$

$$
\Delta\left(\Delta \mathrm{G}_{\mathrm{hyd}}\right)=1.364\left[-\log \left(1+\frac{10^{-10}}{10^{-\mathrm{pH}}}+\frac{\left.\left.10^{-21.994}\right)\right]}{10^{-2} \mathrm{pH}}\right]\right.
$$

for $\mathrm{H}_{2} \mathrm{BO}_{3}$

$$
\Delta\left(\Delta \mathrm{G}_{\text {hyd }}\right)=1.364\left[-\log \left(1+\frac{10-9.18}{10-\mathrm{pH}}+\frac{10-21.89}{10^{-2 \mathrm{pH}}}+\frac{10-35.69}{10^{-3 \mathrm{pH}}}\right)\right.
$$

The adjusted free energy term was statistically shown to be more highly correlated with glass durability than the uncorrected hydration free energy for over 150 glasses tested [23). The $\mathrm{pH}$-adjusted $\Delta \mathrm{G}_{\text {hyd }}$ term is, therefore. preferentially used and glass durability can be calculated from glass composition alone or, more accurately. from glass composition and the $\mathrm{pH}$ of the environment. 


\section{Glass Durability: A Function of Glass Structure}

Although the thermodynamic approach of Newton and Paul [15] assumes that a glass is composed of orthosilicate and oxdde components, no correlation between glass composition and glass structure was made. The relationship between bonding, composition. and durabllity of crystalline and vitreous solids has been examined for over 40 years. Glass sclentists such as Stevels $[27.28]$ have attempted to relate the proportion of non-bridging oxygen atoms (NBO) in a glass network to durability. Similartly, geologists have tried to classify the relative durability (weathering classification) of silicate mineral species on the basis of structural silica-tetrahedra linkages [29.30]. Newton [31] attempted a glass durability classification based on network-bullding versus network-breaking and network modifying (RO) speciation.

Recent studies have demonstrated that the rate-limiting step in sillica-water reactions is breakage of the structural Si-O bonds [5]. Since the reaction mechanism is directly related to the composition of the solld [13], and hence to the number of NBO bonds $[27,28]$ and their strength [5], it is not suprising that the dynamic exchange reactions at the glass-solution interface can be described in terms of the thermodynamic equilibria [6]. This implies that the thermodynamic parameters are representations of the structural energetics of the hydration process and that the relation between the glass structure and durability is a function of the glass lattice energy.

The bond strength is a component of the lattice free energy and an exact expression for the free energy of a glass has been dertved and shown to be dependent only upon the concentration and energy of the bonds present in the structure [32].

Jantzen and Plodinec [22] demonstrated that the thermodynamic free energles of hydration of the orthosilicate and oxdde glass components correlated with both the lonic potential $(\mathrm{Z} / \mathrm{r})$ and the lonic fleld strength $\left(F=Z / s^{2}\right)$ of these species. The relative hydration potential of the species based on $\left(\Delta G_{h y d}\right)_{4}$ or on the lonic fleld strength, groups the species into network-formers, -breakers, and-modifiers. Recent investigations [33] of glass structure have hypothesized that glasses are, indeed. mixtures of sillcate and oxdde component clusters (the strained mixed cluster model).

The correlation of the ionic potential and the lonic field strength with the ( $\left.\Delta G_{\text {hyd }}\right)_{1}$ supports the conclusion that the calculated hydration equations are the thermodynamic representations of the structural energetics of the hydration process [22]. The $\Delta G_{\text {hyd }}$ for over 150 glasses was shown [22.34] to highly correlate with the number of non-bridging oxygen bonds calculated from the glass composition, reinforcing this conclusion. Since the hydration thermodynamic approach assumes that glass structure is a primary function of glass composition, glass structure is not considered as an additional parameter affecting glass durabillty.

\section{EXPERIMENTAL}

\section{Parameterzation of the Factors Affectine Glass Durability}

During laboratory experimentation, the following parameters are known [1] to affect glass durability:

(1) exposed surface area (SA) of the solid

(2) volume (V) of the leaching solution

(3) frequency of replenishing/changing the solution.

$$
\text { e.g. time duration ( } t \text { ) of the experiment }
$$

(4) temperature (T) of leaching in ${ }^{\circ} \mathrm{C}$

(5) glass composition 
Initially, parameters 1-4 were kept constant and only the glass composition was varied. Over 150 different glasses of widely varying compositon were examined. Glass monollths with a geometrically measured surface area of $4 \mathrm{~cm}^{2}$ were immersed in $40 \mathrm{~cm}^{3}$ of high-purity water (ASTM Type I) according to the MCC-1 leach test protocol [35]. In this manner, the SA/V ratio was always kept constant. The durability test was performed at $90^{\circ} \mathrm{C}$ for 28 days duration. All the durabillty tests were run in duplicate.

In later studies, the glass composition was kept constant by choosing a representative "reference set" of about 10 glasses. The test temperature was kept constant at $90^{\circ} \mathrm{C}$, but the test duration was varled. Glass monoliths and crushed glasses were tested at vartous time durations. Crushed glasses wetghing 1.5 grams were immersed in $40 \mathrm{~cm}^{3}$ of high-purity water (ASTM Type l) according to the MCC-3 leach test protocol [34]. The SA/V ratio was varied by testing glasses crushed to varlous mesh sizes. The detalls are given elsewhere [23].

Elemental concentrations in solution were measured by inductively coupled plasma (ICP) and by atomic adsorption (AA) spectroscopy. The concentrations are reported as normalized elemental mass losses, e. g. $\mathrm{NL}_{1}$. released from the glass in grams of glass per square meter of glass surface area) according to the MCC protocols [34]. This has the advantage that the release concentrations in parts per million are normalized by the weight fraction of that element present in the glass by the formalism

$$
\mathrm{NL}_{1}=\frac{\mathrm{C}_{1}}{\mathrm{~F}_{1} \cdot(\mathrm{SA} / \mathrm{V})}
$$

where

$$
\begin{aligned}
& \mathrm{NL}_{\mathrm{l}}=\text { normalized elemental mass loss (gglass } / \mathrm{m}^{2} \text { ) } \\
& \text { solution }\left(g_{1} / \mathrm{m}^{3}\right) \\
& F_{1}=\text { fraction of element "in in the glass } \\
& \begin{array}{ll}
\mathrm{SA} & =\text { (gpechomen surface area }\left(\mathrm{m}^{2}\right) \\
\mathrm{V} & =\text { solution volume }\left(\mathrm{m}^{3}\right)
\end{array}
\end{aligned}
$$

The $\mathrm{pH}$ of the leachates was measured: for experiments in high-purity water, the $\mathrm{pH}$ excrusions were considered to be controlled by the glass composition as discussed above. For simulated groundwater leachants, the measured $\mathrm{pH}$ was found to be controlled by the groundwater chemistry for even the most alkali-rich (poorly durable) glasses [26].

\section{RESULTS AND DISCUSSION}

\section{Glass Durability: A Function of Glass Composittion}

Over 150 different glasses were leached in duplicate by the MCC-1 test protocol. These included natural obsidians, tektites, basalts, pure $\mathrm{SiO}_{2}$. pyrex, modern window glass, and simulated medieval window glasses from the European Sctenc Foundation (ESF). Four actual ancient Roman and Islamic glasses (Jalame ca. 350 A. D.. Nishapur 10-1 Ith century A. D., and Gorgon 9-11th century A.D.) obtained from the Corning Museum of Glass were also included in this study. The $\Delta G_{\text {hyd }}$ was calculated from the analyzed glass compositions and the solution $\mathrm{pH}$. Statistically determined regression equations and the 95\% upper and lower confidence limits were determined $[23-24]$ for binary combinations of the following varlables: $\Delta G_{h y d} . \log \left(N L_{S i}\right), \log \left(N L_{B}\right)$, and $-\log \left(H^{+}\right)$or $p H$. Logarithmic concentrations were used throughout the statisttcal analysis because the ton concentrations are assumed to be proportional to the ideal ton activities in the thermodynamic treatment [24]. 
A simple linear regression of the $\Delta G_{\text {hyd }}$ and $\log \left(N_{S} L_{S 1}\right)$ data demonstrated that glass durability could be determined from glass composition for the 304 experimental data points (Figure la). The more negative the $\Delta \mathrm{G}_{\text {hyd }}$ term, the less durable the glass and the more $\mathrm{Si}$ is released to solution. Using this approach, the durabllity of the most durable nuclear waste glasses is $-10^{6}$ years by comparison with the durability of basalts of $\sim 10^{6}$ years [22]. These waste glasses are slightly less durable than the high-temperature tektite and obsidian glasses. The least durable waste glasses are comparable to the most durable simulated medieval window glasses of $\sim 10^{3}$ years. In this manner, the durabllity of nuclear glasses can be interpolated to be $>10^{3}$ years and $\leq 10^{6}$ years.

The computer generated equation of best fit relating glass composition to silicon released from the glass is plotted in Figure 1 and the mathematically determined slope is -0.2240 . The computer-calculated $95 \%$ confidence interval is shown by the dotted lines. The statistical analysis also revealed the primary contribution to the $95 \%$ confldence interval was from the $\Delta G_{\text {hyd }}$ term: errors in glass analysis are more significant than errors in leachate analyses [23].

Since many natural and man-made glasses do not contain boron, only 140 experimental observations (70 glasses) could be statistically fit (Figure 1b). Boron release follows a pattern simllar to that of silicon: the more negative the $\Delta G_{\text {hyd }}$ term the less durable the glass and the more boron is released to solution. The relative positions of the obsidian, tektite, nuclear waste glasses, and the medieval window glasses remains the same.

The slope relating $\Delta G_{\text {hyd }}$ and $\log \left(N_{B}\right)$ is -0.2795 . This is similar to the -0.2240 slope calculated for the relation between $\Delta G_{h y d}$ and $\log \left(N_{S i}\right)$. The high silica glasses, including the tektites and obsidians, contain very little boron and, hence, the positive free energy portion of the curve has a poorer statistical fit than the negative portion, which alters the slope somewhat. Since the slopes relating $\Delta G_{\text {hyd }}$ to $\log \left(N L_{S i}\right)$ and to $\log \left(N L_{B}\right)$ are similar, it is not suprising that a plot of $\log \left(\mathrm{NL}_{S_{1}}\right)$ and $\log \left(\mathrm{NL}_{\mathrm{B}}\right)$ has a slope of $\sim 1[23,24]$. This is anticipated for glasses which undergo congruent dissolution. Although, the regression equations have simllar slopes, the absolute value of $\log \left(\mathrm{NL}_{\mathrm{B}}\right)$ is greater than $\log \left(\mathrm{NL}_{\mathrm{SI}}\right)$ for a glven glass as predicted from the relative ion activities of these solution species.

Newton and Paul [15] leached ground ESF medieval window glasses in water at $25^{\circ} \mathrm{C}$. The glass contacted the solution for only 24 hours and the amount of $\mathrm{K}_{2} \mathrm{O}$ extracted was measured. $A$ plot of the calculated $\Delta \mathrm{G}_{\mathrm{hyd}}$ and $\log \mathrm{K}_{2} \mathrm{O}$ in ppm gave a slope of -0.212 [2]. The same ESF medieval window glassses were leached by the MCC-1 procedure and are included in Figure 1a. Since they do not contain boron, they do not appear in Figure 1b. A

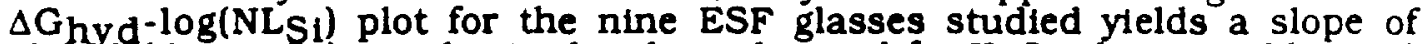
-0.288 (Figure 2a), simllar to the slope obtatned for $\mathrm{K}_{2} \mathrm{O}$ release. Bibler and Jantzen [36] have shown that $\mathrm{SI}_{1} \mathrm{~B}, \mathrm{Na}$, and $\mathrm{K}$ released to solution during MCC-3 type crushed glass tests all correlate well with $\Delta G_{\text {hyd. The hydration }}$ thermodynamic model is, therefore. sufficiently sensitive to reaction progress measured as release concentrations.

Newton and Paul [15] also demonstrated that the free energy of hydration appeared to correlate with the logarithm of the loss of thickness of vartous glasses measured in $\mathrm{mm} /$ century. The effects of long-term weatherting were simulated by immersing the glasses in water of $\mathrm{pH} 7$ at $25^{\circ} \mathrm{C}$. This correlatton gave a slope of about -0.289 , in agreement with the data shown for the response of $\Delta \mathrm{G}_{\text {hyd }}$ with $\mathrm{K}_{2} \mathrm{O}$ in the leachate solutions of crushed glass tests [15] and with $\log \left(\mathrm{NLS}_{\mathrm{S}}\right)$. Analysis of ten of these simulated ESF glasses which were burled in a limestone mound in Ballidon, UK ( $\mathrm{pH}-9.5$ ) for 5 years [37.38] also correlated with the $\Delta \mathrm{G}_{\text {hyd }}$ [39]. Since the $\mathrm{pH}$ of the environment was kept constant, the $\Delta \mathrm{G}_{\text {hyd }}$ could be calculated from the glass composition alone or from composition and groundwater $\mathrm{pH}$. The depths of attack were not measured very accurately [38] and a slope of -0.421 (Figure $2 b)$ was obtained. When the laboratory release rate. NLSt. was plotted against the in-situ depth of attack for these same glasses. a correlation with a slope of -1 was obtained (Figure 2c). 

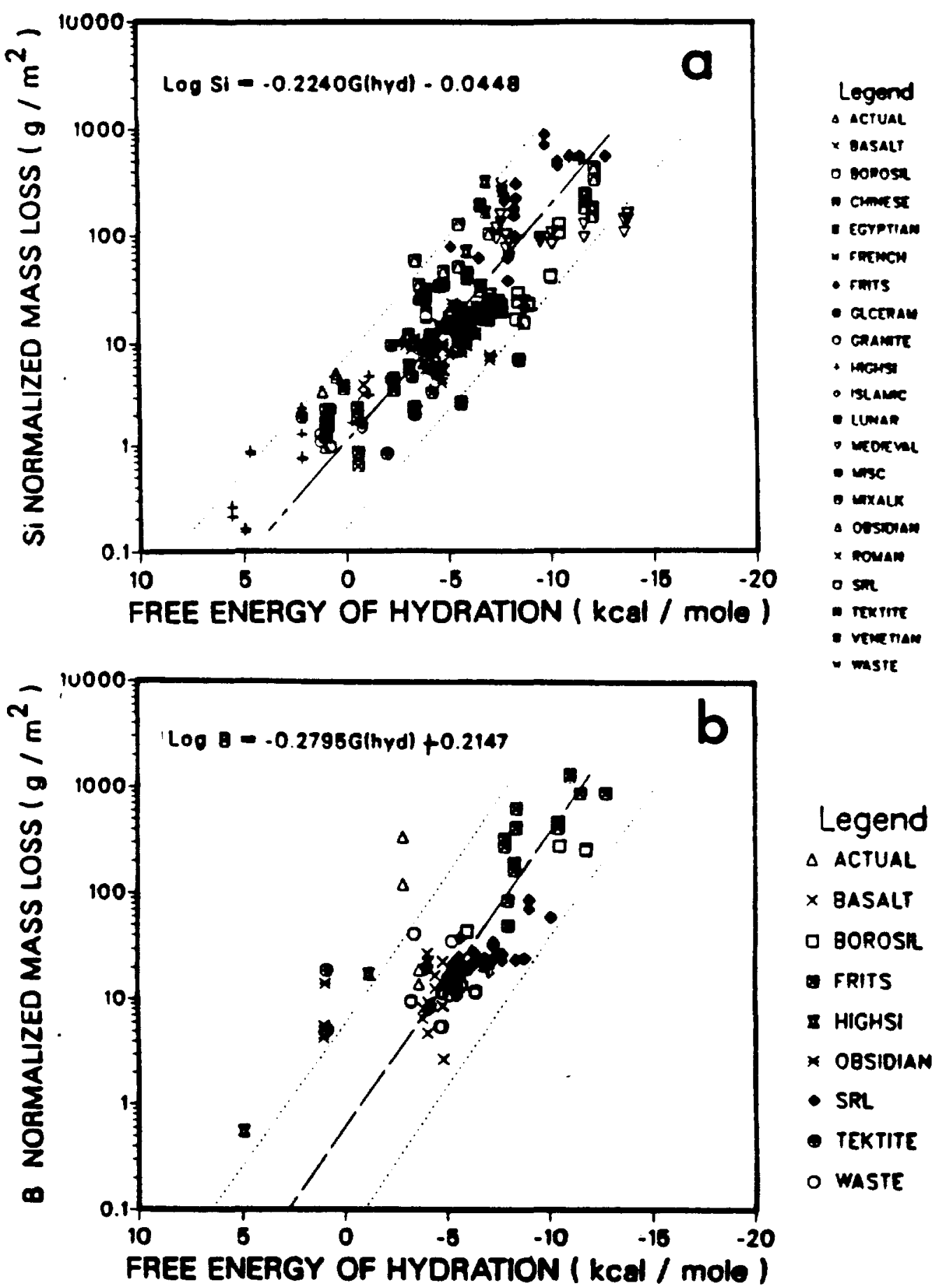

Figure 1a. Linear regression plot of over 300 experiments relating glass composition ( $\Delta \mathrm{G}_{\mathrm{hyd}}$ ) to glass durability (expressed as Si lost from the glass to the leachate solution in a 28 day laboratory experiment).

1b. Linear regression plot of 140 experiments on boron-containing glasses relating glass composition ( $\Delta \mathrm{G}_{\mathrm{hyd}}$ ) to glass durability (expressed as B lost from the glass to the leachate solution in a 28 day laboratory experiment). 

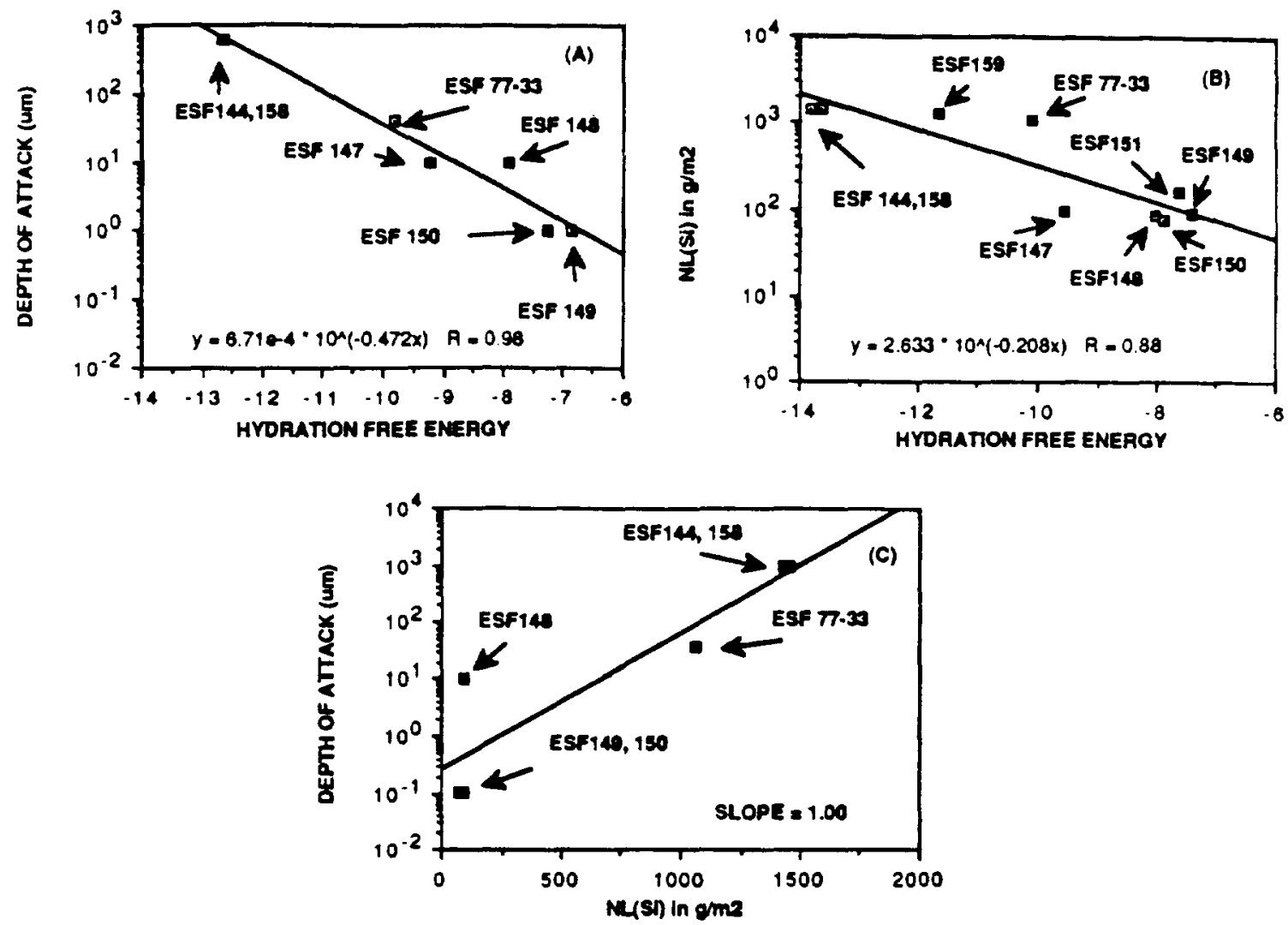

Figure 2a. Application of Hydration thermodynamics to MCC-1 laboratory test data for European Science Foundation medieval window glasses.

2b. Application of hydration thermodynamics to "depth of attack" of the glass surface after burial in the United Kingdom for 5 years.

2c. Comparison of the laboratory and in-situ data from $2 a$ and $2 b$.

The relative durabllitles of the ESF medieval window glasses predicted from $\Delta G_{\text {hyd }}$ are the same when plotted against

(1) $\mathrm{K}_{2} \mathrm{O}$ released to solution in a 24 hour laboratory experiment

(2) Si released to solution in a 28 day laboratory experiment

(3) loss of thickness observed in "long-term" laboratory experiments

(3) depth of attack observed in 5 year in-situ burial experiments

More importantly, the relative durabilities of the medieval window glasses predicted by hydration thermodynamics are the ones observed to occur in nature during weathering [15].

\section{Glass Durability. A Function of Glass and Groundwater (Solution) Composition}

Many groundwaters are sllica saturated from interactions with sllicarich rocks such as tuff, basalt. granite and/or silica-rich solls. Leaching of nuclear waste glasses in silicate saturated groundwaters has been found to minimize the dissolution of the glass [40]. Automatic dishwasher powders are laced with silica to saturate the washing solution and minimize attack on modern glassware. These empirical observations are supported by the data of Grambow [41.42], which suggests that dissolution of silicate and borosillicate glasses can be described by the activity diagrams for the dissolution of amorphous silica. The activity-pH diagrams provide the fundamental correlation between minimum solubility of a spectes in solution and the free energy $[12,24,43]$. 
In the initial studies of glass durabllity as a function of glass composition [20-25], leachants of high-purtty water were used. In order to quantify the effects of groundwater (solution) chemistry on glass durability. a "reference set" of $\sim 10$ glasses were chosen for study with the thermodynamic hydration approach. The glass composittons included pure $\mathrm{SiO}_{2}$ tektites, basalts, waste glasses, two ESF glasses, and a poorly durable frit glass. The test temperature, test duration ( 28 days), and $S A / V$ ratio were kept the same as the studies in high-purtty water.

The sllica-saturated groundwaters were found to minimize the amount of silica released to solution as found in previous experiments [44]. The chemistry of the groundwater buffered the leachate $\mathrm{pH}$ : even the poorest glass, the frit glass. did not cause leachate $\mathrm{pH}$ excursions.

Since the $\Delta G_{\text {hyd }}$ defined in the high-purity water experiments is calculated from the glass composition and the solution $\mathrm{pH}$, the linear equation determined is an expression of the response of both glass and solution $\mathrm{pH}$ (Figure 1a). In the buffered groundwater experiments, the constant $\mathrm{pH}$ altered the calculated $\Delta \mathrm{G}_{\text {hyd }}$ term, but the buffering capacity of the groundwater also lowered the Si released from the glass. The data from the groundwater leachates. therefore, superimposes on the linear equation defined by the high-purity water experiments (Figure 3 ) [26]. When the groundwater $\mathrm{pH}$ and the glass composition are known. the performance of a given glass in nature can be predicted by hydration thermodynamic theory. If the groundwater $\mathrm{pH}$ is constant, then only the glass composition need be known in order to determine "relative" glass durabilities in a given environment.

The hydration thermodynamic model was also applied to in-situ measured depth of attack for waste glasses which had been exposed to silica saturated groundwaters for two years [44]. The waste glasses had been burted in a granitic mine in Stripa. Sweden to simulate burlal of waste glass in a granitic repository. The glass monoliths were emplaced in boreholes in the mine which were allowed to fill with the natural stlicate groundwater. The glass-groundwater environment in the borehole was kept at $90^{\circ} \mathrm{C}$ to simulate the heat of radioactive decay. After 2 years burial, the depth of attack was measured accurately by secondary ion mass spectroscopy (SIMS) analysis. The slope of in-situ depth of attack and $\Delta G_{\text {hyd for the waste }}$ glasses buried in Stripa was -0.270 [40], similar to the slopes given for the elemental release concentrations in the high-purity water experiments and the ESF glass depths of attack.

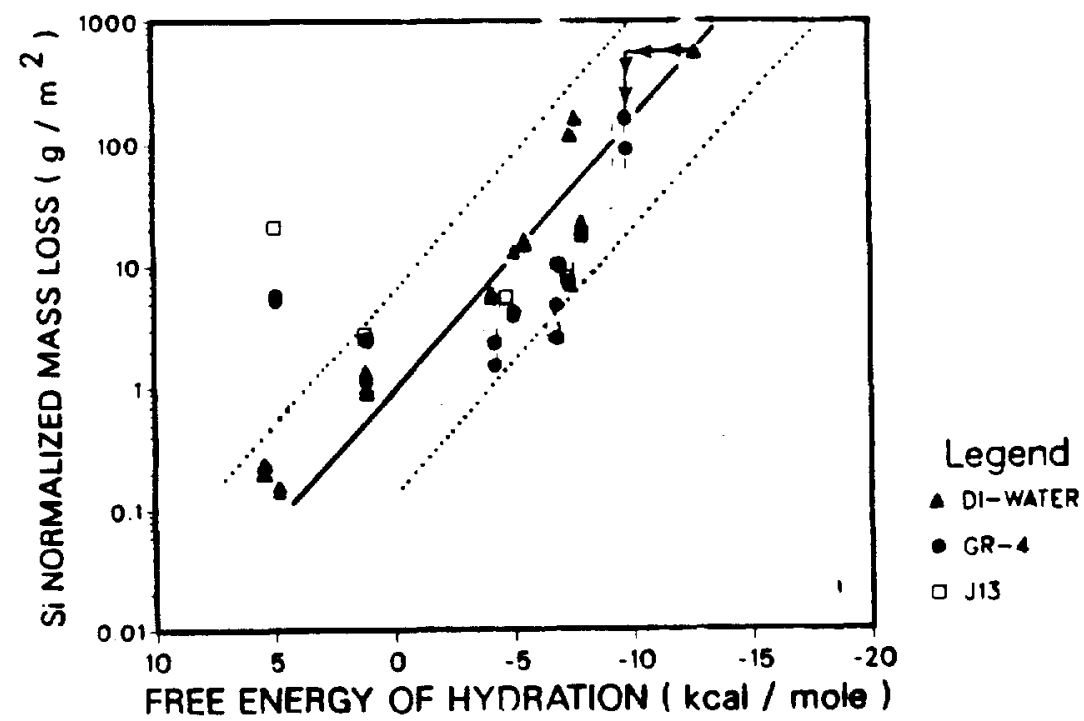

Figure 3. Comparison of the hydration thermodynamic data for a "reference set" of glasses tested by the MCC-1 test protocol. The equation of best fit and the $95 \%$ conflence limits were defined by the MCC-1 data in detonized water. The data for silica-saturated tuff groundwater $(\mathrm{J}-13)$ and basaltic groundwater $(\mathrm{GR}-4)$ are shown to revert to the same regression equation. 


\section{Glass Durablitty: A Function of the Kinetic (SA/V) -t Parameters}

The time-dependent release of an element from a given glass to the leachate was found to be a smooth function of the $(\mathrm{SA} / \mathrm{V}) \bullet t$ parameter [45-46]. Crushed glass tests are glass dominated, e.g. the leachate chemistry is dominated by the large amount of glass surface area, which makes the response of these tests very senstive to glass composition. The hydration thermodynamic theory was, therefore, applied to crushed glass experiments (MCC-3 leaching test protocol) in high-purity water [23, 47]. It was noted [23] that the slopes of $\log \left(N_{L} S_{1}\right)-\Delta G_{h y d}$ for monolithic tests (low $\left.S A / V \bullet t\right)$ and crushed glass tests (high SA $/ V \circ t)$ were the same. This occurs because the test geometry alters only the kinetic reactivity parameters, e.g. surface area (SA), leachant volume (V), and the length of time that the glass has contacted the leachant (t). The kinetic reactivity parameters alter the rate at which the saturation ion concentrations are approached. The slope represents the natural logarithm of the theoretical slope, (1/2.303 RT), for the rate of glass dissolution [48].

Measures of reaction progress such as $\log \left(\mathrm{NL}_{\mathrm{Si}}\right)$ or $\log (\mathrm{S} 1)$ in $\mathrm{ppm}$ have been shown to be a function of (SA/V) $\bullet$ [23] for the sequence of "reference glasses" discussed above. The $\log \left(\mathrm{NL}_{\mathrm{Si}}\right)$ versus (SA/V)・t curves for the varlous glasses increase in the order predicted by their relative $\Delta G_{\text {hyd }}$ values [23]. Since $\log \left(\mathrm{NL}_{S_{1}}\right)$ is a function of both (SA/V) $\bullet$ t and $\Delta \mathrm{G}_{\text {hyd. a plot of }}$ over 120 data points collected on the "reference set" of glass was plotted in three dimensional $\log (\mathrm{NLS1})-(\mathrm{SA} / \mathrm{V}) \cdot \mathrm{t}-\Delta \mathrm{G}_{\mathrm{hyd}}$ space. The data formed a plane which could be fitted statistically with a spline function (Figure 4) [49]. The slopes of the $\Delta G_{\text {hyd }}-\log \left(N_{S}\right)$ plots for monoldthic tests (low SA/V•t) and for crushed glass tests (high SA/V•t) are similar because they intersect the three-dimensional plane at constant (SA/V) •t.

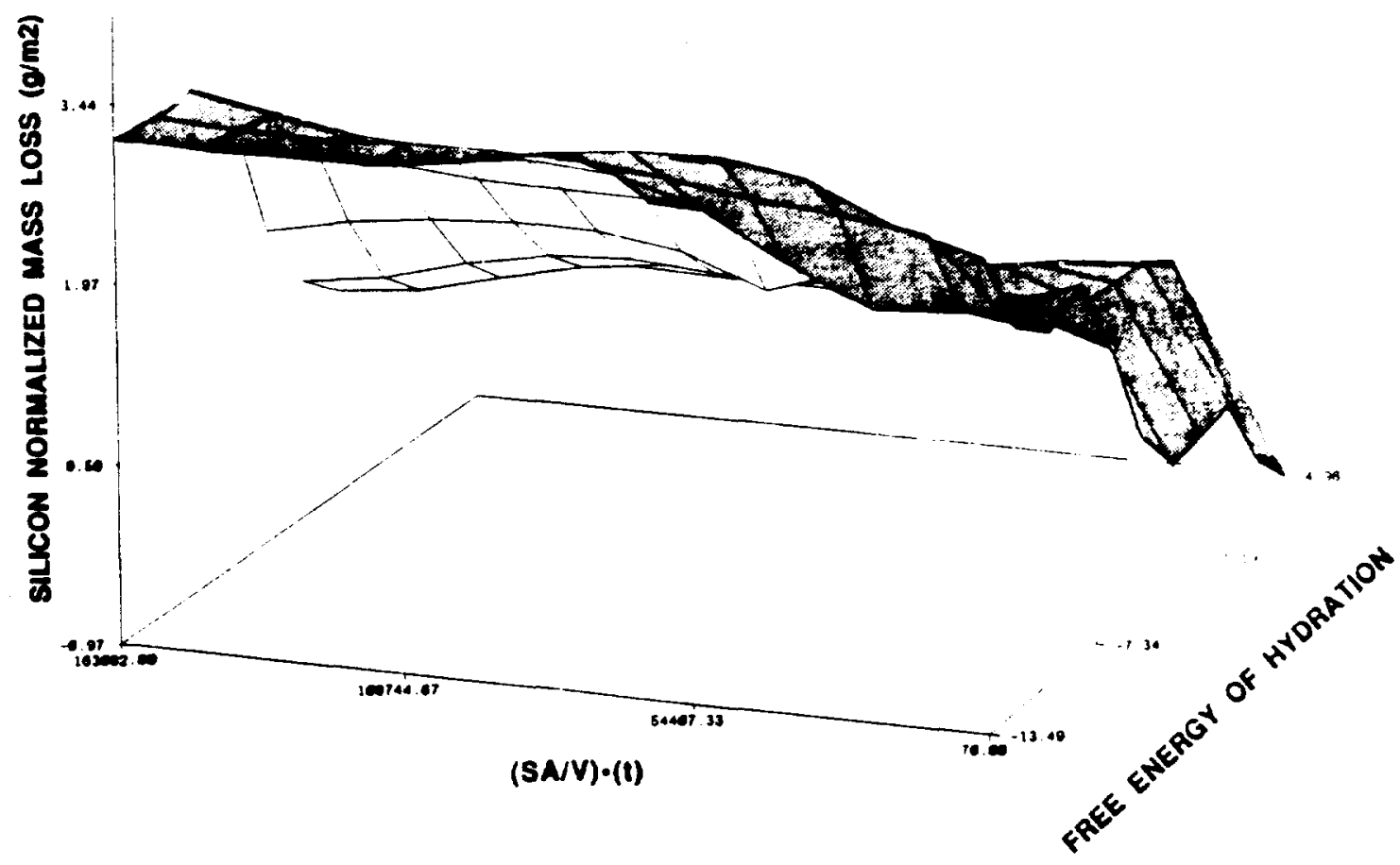

Figure 4. Computer-generated spline funciton for 122 durability experiments at low (SA/V) high (SA/V) $\bullet$ [MCC-3 test protocol for crushed glass). The data form

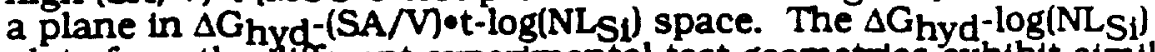
plots from the different experimental test geometries exhibit similar slopes because they are slices through $\Delta \mathrm{G}_{\text {hyd }}$-(SA/V) $\bullet-\log \left(\mathrm{NL}_{\mathrm{SI}}\right)$ space at constant (SA/V) •t. 


\section{Glass Durabillty: A Function of Solution oH and Oxidation Potential (Eh)}

Equilibrium pH-electrochemical potential (E or $E$ h) diagrams were developed by Pourbalx $[11]$ to describe the effects of aqueous environments on corrosion of metals. Pourbalx diagrams, referred to as $\mathrm{pH}-\mathrm{Eh}$ diagrams. have been developed by geochemists to depict the stability relations among solld phases [50,51] and to assess mineral (rock) stabllity during weathering [12]. The thermodynamic approach of Pourbaix which is dependent on thermodynamically calculated phase stability boundaries can be combined with the hydration thermodynamic approach to derive a generic Pourbatx diagram for glass dissolution.

The statistically-determined relationships between $\mathrm{pH}-\Delta \mathrm{G}$ hyd $\mathrm{pH}-\log \left(\mathrm{NL}_{\mathrm{SI}}\right)$, and $\mathrm{pH}-\log \left(\mathrm{NL}_{\mathrm{B}}\right)$ based on response of the 150 glasses during the MCC-1 durabillity tests can be used to quantifly the generic Pourbalx diagram for glass dissolution $[24,25]$. This is supported by the data of Grambow [41.42] which suggests that the dissolution of all silicate and borosilicate glasses can be described by the activity diagram for the dissolution of amorphous sillica. The known effects of solution $\mathrm{pH}$ and Eh on nuclear waste glass dissolution and surface layer formation can then be used to thermodynamically calculate the pertinent phase stability fields for dissolution of this type of glass. This type of approach conceptually unifies all glass dissolution as a function of solution $\mathrm{pH}$ and $\mathrm{Eh}$.

Activity-pH (or activity-Eh) dlagrams provide the fundamental correlation between ion concentrations in solution and the free energy of a hydration reaction. Although solubility concentrations differ from the activities by a factor, $\gamma$, known as the activity coefficient [12]. If $\gamma$ is approxdmately equal to one, then the ion activity approximately equals the ion concentration. The factor $y$ is dependent on the ionic strength of the solution and is a function of the multiple hydration, ionization, and complexation reactions that the ion partictpates in. However, the activity-pH diagrams provide the fundamental correlation between minimum solubility of an ton in solution and the free energy [12.43]. In this manner, a three dimensional Pourbaix diagram can be constructed. The three dimensional representation of activity (concentration), $\mathrm{pH}$, and Eh is shown schematically [51] in Figure 5 for spectes which are

- independent of Eh

- independent of $\mathrm{pH}$

- Independent of both $\mathrm{Eh}$ and $\mathrm{pH}$

- dependent on both Eh and pH.

Glass components which respond to solution Eh are generally multivalent redox sensitive species. Spectes such as $\mathrm{B}$ and $\mathrm{SI}$ are more sensitive to changes in $\mathrm{pH}$ than Eh [24].

The influence of $\mathrm{pH}$ on the activity of vitreous sillca can be thermodynamically calculated from the equilibrium constants for the hydration of $\mathrm{SiO}_{2}$ to sllicic acid and the equilibrium constants for silletc acid dissociation $[2,11]$. Likewise, the activity-pH relations for vitreous $\mathrm{B}_{2} \mathrm{O}_{3}$ hydration can be calculated from the equilibrium constants for the hydration of vitreous $\mathrm{B}_{2} \mathrm{O}_{3}$ to bortc acid and the equillbrium constants for bortc acid dissociation [24]. The hydration of vitreous sllica (or vitreous boric oxide) is independent of Eh, and hence the activity-pH diagrams provide the fundamental correlation between stlica (or boron) concentration in solution and the free energy. Sllicon and boron concentration-dependent contours would, therefore, parallel the Eh axds as shown in Figure 5a [24,11]. 

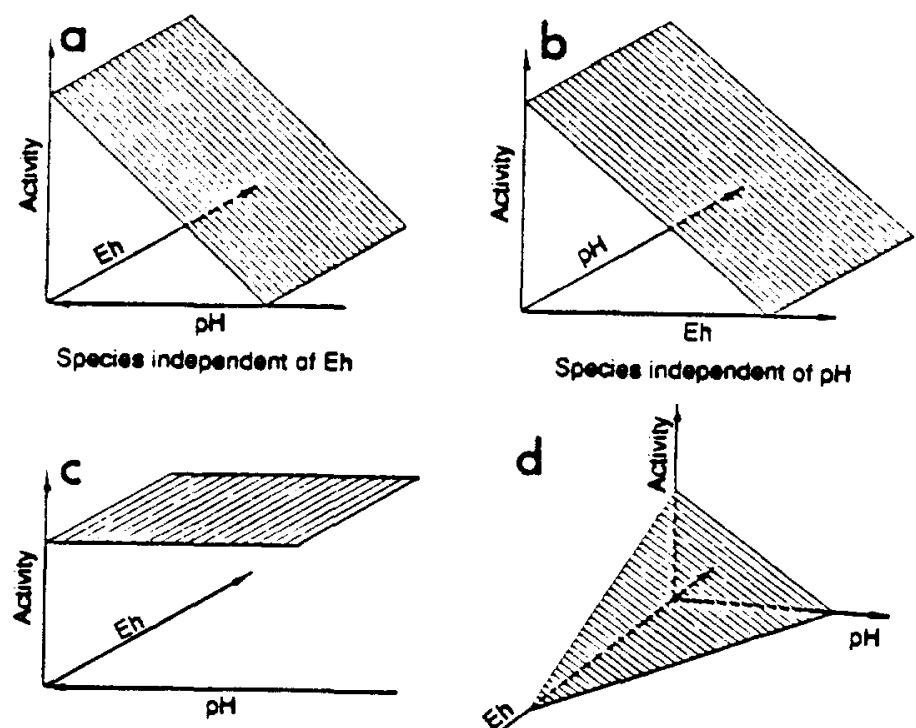

Species hidisencient of both Eh and ph

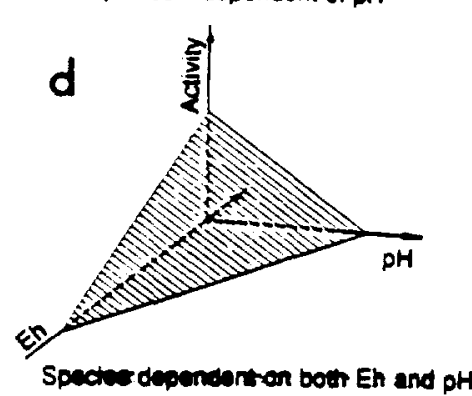

Figure 5. Three dimensional representation of the relations between the activity of a species with solution $\mathrm{Eh}$ and $\mathrm{pH}$ (after Krumbein and Garrels [51]). Note the different behavior of spectes which are dependent or independent of solution Eh and/or pH.

For the 300 individual glass durability tests, the regression equations were statistically calculated [24] for binary combinations of the following varlables: $\Delta G_{\text {hyd }}, \log \left(\mathrm{NL}_{S_{1}}\right), \log \left(\mathrm{NL}_{\mathrm{B}}\right)$, and $\mathrm{pH}$. Several regressors were found to be nearly linear combinations of other regressors in the data base. e.g. colinear. The variables $(n=4)$ were examined in $n-1$ combinations. Combinations of $n-1$ variables have three degrees of freedom. However, the three degrees of freedom are limited by the strong vartable pair interactions between $\Delta G_{\text {hyd }}-\mathrm{pH}, \log \left(\mathrm{NL}_{S_{1}}\right)-\mathrm{pH}$, and $\log \left(\mathrm{NL}_{\mathrm{B}}\right)-\mathrm{pH}$ [24]. The variable pair interactions 1mpart an additional restriction on any n-1 combination so that the degrees of freedom is reduced to $n-2$ or 2 .

The colinearity between the regressors is caused by the fundamental thermodynamic relationships among $\Delta G_{h y d}$, the solution $p H$, and the concentration of species in solution. The $\log \left(\mathrm{NL}_{\mathrm{S1}}\right) . \Delta \mathrm{G}_{\mathrm{hyd}}$, and the $\mathrm{pH}$ are highly colinear because the $\mathrm{pH}$ and $\Delta \mathrm{G}$ hyd are related through the Nernst equation [24]. In addition, $\log \left(\mathrm{NL}_{\mathrm{Si}}\right)$ is related to the $\mathrm{pH}$ through the activity-pH relationship. The $\log \left(\mathrm{NL}_{\mathrm{S}_{1}}\right), \log \left(\mathrm{NL}_{\mathrm{B}}\right)$, and the $\mathrm{pH}$ are highly colinear because of the restriction imposed by congruent dissolution [24]. Each of these solution species is colinear with $\mathrm{pH}$ because of the $\mathrm{pH}$ dependence of the saturation lon activities. The $\log \left(\mathrm{NL}_{S_{1}}\right)$ and $\log \left(\mathrm{NL}_{\mathrm{B}}\right)$ are related to $\Delta G_{\text {hyd }}$ through the equllibrium constants for the hydration of $\mathrm{SiO}_{2}$ and $\mathrm{B}_{2} \mathrm{O}_{3}$, and the equillbrium constants for sllictc actd and borlc acid dissociation. Therefore, combinations of the following $n-1$ variables can be defined by the slopes between any binary patr of variables:

$$
\begin{array}{ll}
\text { - } & \log \left(N_{S I}\right)-\Delta G_{h y d}-p H \\
\text { - } & \log \left(N L_{B}\right)-\Delta G_{h y d}-p H \\
\text { - } & \Delta G_{\text {hyd }}-\log \left(N N_{S 1}\right)-\log \left(N L_{B}\right) \\
& \text { pH }-\log \left(N L_{S 1}\right)-\log \left(N L_{B}\right)
\end{array}
$$


Over the limited $\mathrm{pH}$ range $(-5-13 \mathrm{pH})$ of the delonized water experiments, the statistically determined slopes between $\mathrm{pH}$ and the rematning three variables gave [24] the following:

$$
\begin{array}{ll}
\mathrm{pH} & =-0.489 \Delta \mathrm{G}_{\text {hyd }}+6.12 \\
\log \left(\mathrm{NL}_{\mathrm{S1}}\right) & =+0.429 \mathrm{pH}-2.73 \\
\log \left(\mathrm{NL}_{\mathrm{B}}\right) & =+0.416 \mathrm{pH}-2.31
\end{array}
$$

Because of the collnearity relationships between $\mathrm{pH}-\log \left(\mathrm{NL}_{\mathrm{Si}}\right)$ and $\mathrm{pH}-\log \left(\mathrm{NL}_{\mathrm{B}}\right)$, a three dimensional $\mathrm{Eh}-\mathrm{pH}$-concentration diagram similar to the schematic Eh-pH-activity diagram in Flgure 5 can be constructed. The concentrations of $\mathrm{SI}$ and $\mathrm{B}$ in solution have been shown experimentally $[52.53]$ to be almost completely independent of the solution $E h$. The $E h$ independent equillbria will, therefore, parallel the $\mathrm{Eh}$ axis as shown schematically in Figure 5a. Isopleths of constant solution concentration can be contoured on the Eh-pH plane from the statistically determined slopes given in Equations 6 and 7 . A quantitative Pourbalx diagram for glass dissolution can, therefore, be developed (Figure $6 \mathrm{a}$ and $6 \mathrm{~b}$ ).
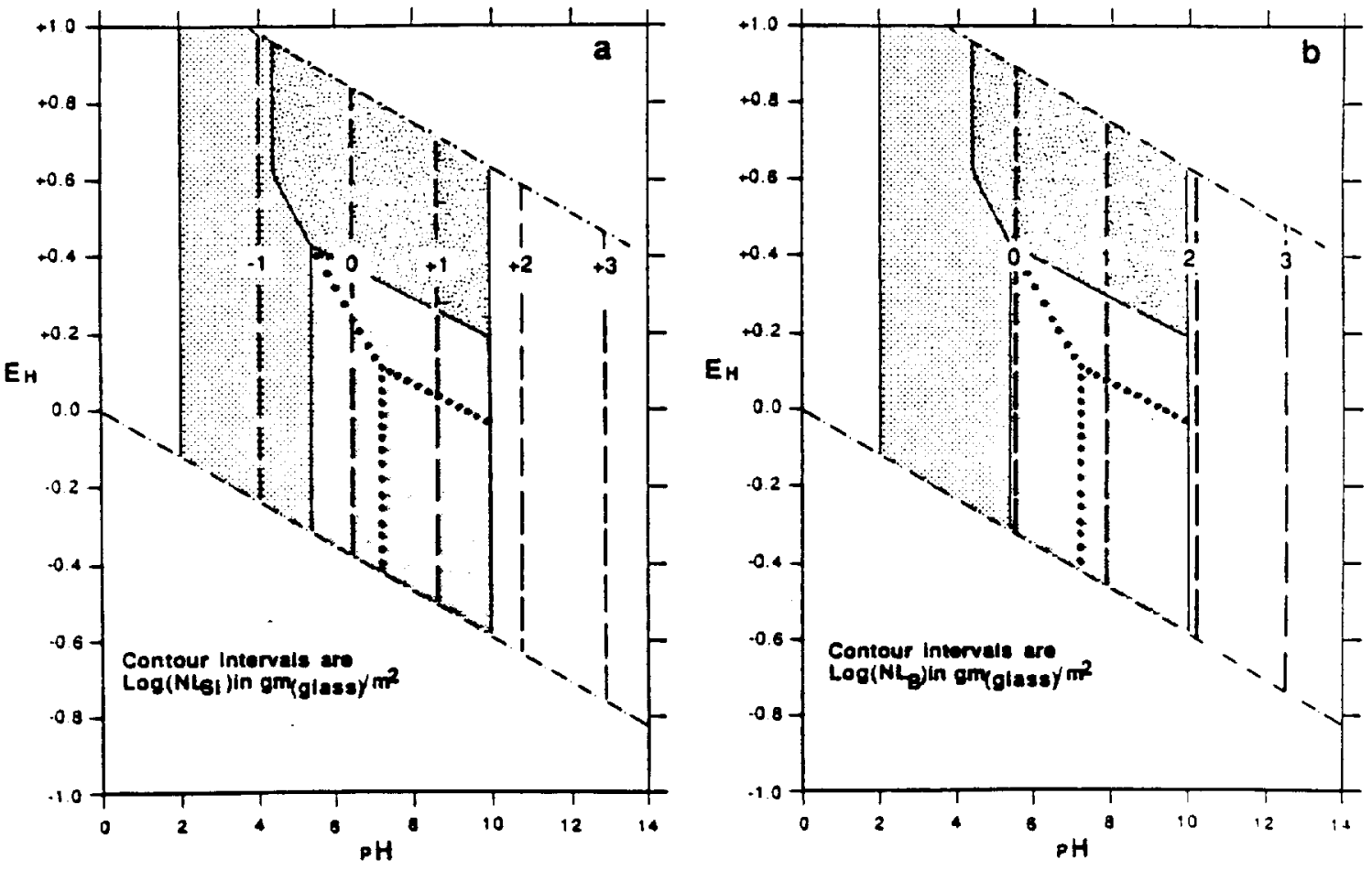

Figure 6a. Pourbalx diagram for glass dissolution based on Eh independent release of sllicon to solution for over 300 glasses studied. Contour intervals were determined from the slope of Equation 6 in text.

6b. Pourbaix diagram for glass dissolution based on $\mathrm{Eh}$ independent release of boron to solution for over 140 glasses studied. Contour intervals were determined from the slope of Equation 7 in text. 
Because of the relation of $\Delta \mathrm{G}_{\mathrm{hyd}}$ to Eh and $\mathrm{pH}$ through the Nernst equation [24] and the colinearity of $\Delta G_{h y d}$ (here $\Delta G_{\text {hyd }}$ is calculated only Eh-pH- $\Delta G_{\text {hyd }}$ diagram can be dertved. Since $\Delta G_{\text {hyd }}$ was theoretically shown [24] to be relatively insensitive to solution $\mathrm{Eh}$, it can also be contoured parallel to the Eh axds on a Pourbaix diagram for glass (Figure 6c). The statistically determined $\Delta G_{h y d}-\mathrm{pH}$ slope given in Equation 5 is used to determine the contour interval.

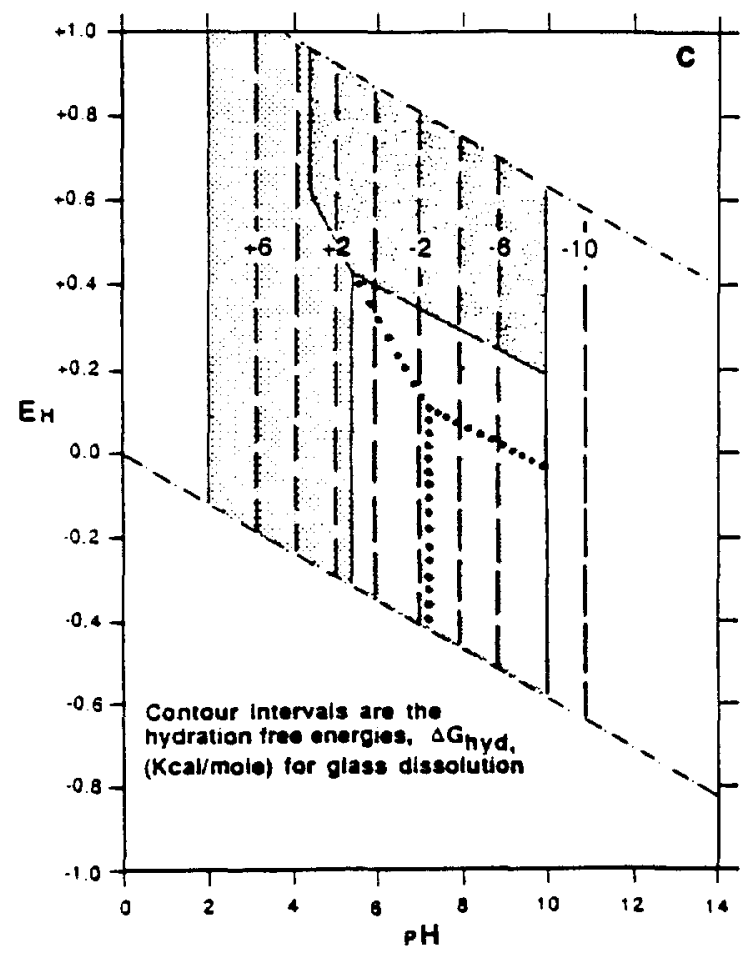

Figure 6c. Pourbalx diagram for glass dissolution based on Eh independent $\Delta \mathrm{G}_{\text {hyd }}$ for over 300 glasses studied. The $\Delta G$ hyd term was calculated from glass composition and environmental pH. Contour intervals were determined from the slope of Equation 5.

The shaded stability fields shown in Figures $6 a-6 c$ relate to the observed phase stability fields and surface layer formation observed for nuclear waste glass dissolution (Figure 7a). A similar stability field diagram is shown in Figure $7 \mathrm{~b}$ for high sillica glasses. The calculated stabllity fields will vary depending on glass type, but the quantification of the Pourbaix diagram is generic. The alkaline boundary of active corrosion is defined by the dissociation $\mathrm{H}_{2} \mathrm{SiO}_{3} / \mathrm{HSiO}_{3}$ boundary and is calculated for $\mathrm{H}_{2} \mathrm{SiO}_{3}=$ $10^{-4} \mathrm{M}$. Higher concentrations of $-10^{-3}$ move the $\mathrm{H}_{2} \mathrm{SiO}_{3} / \mathrm{HSIO}_{3}$ - active corrosion boundary to higher $\mathrm{pH}$ values. In other words, Pourbaix diagrams provide the thermodynamic rationale of why glass dissolution at higher $\mathrm{pH}$ values can be minimal in silica saturated groundwaters. The active dissolution boundary shifts, depending on the concentration of silica present.

The detalls of the stabllity field calculations are given elsewhere $[24,25]$. The pH dependence of the acttve corrosion fields is a function of the silica content of the glass $[54,55]$. However, the contribution of the glass compositon to the surface layer formation is fundamentally accounted for in the calculation of the hydration free energy from glass composition because (1) all glasses have some type of surface layer formation [56], (2) the type of surface layer formation is a function of the glass composition [56], and (3) the types of surface layers correlate with hydration free energy [22]. Because of the relationship of the free energy to the activities of all the species in a glass, the hydration free energy calculates the relative roles of amorphous silica dissolution as modifled by surface layer formation. The data support the hypothesis of Grambow [41.42] that the dissolution of all silicate-based glasses can be descrtbed by the activity diagrams for the dissolution of amorphous silica. 

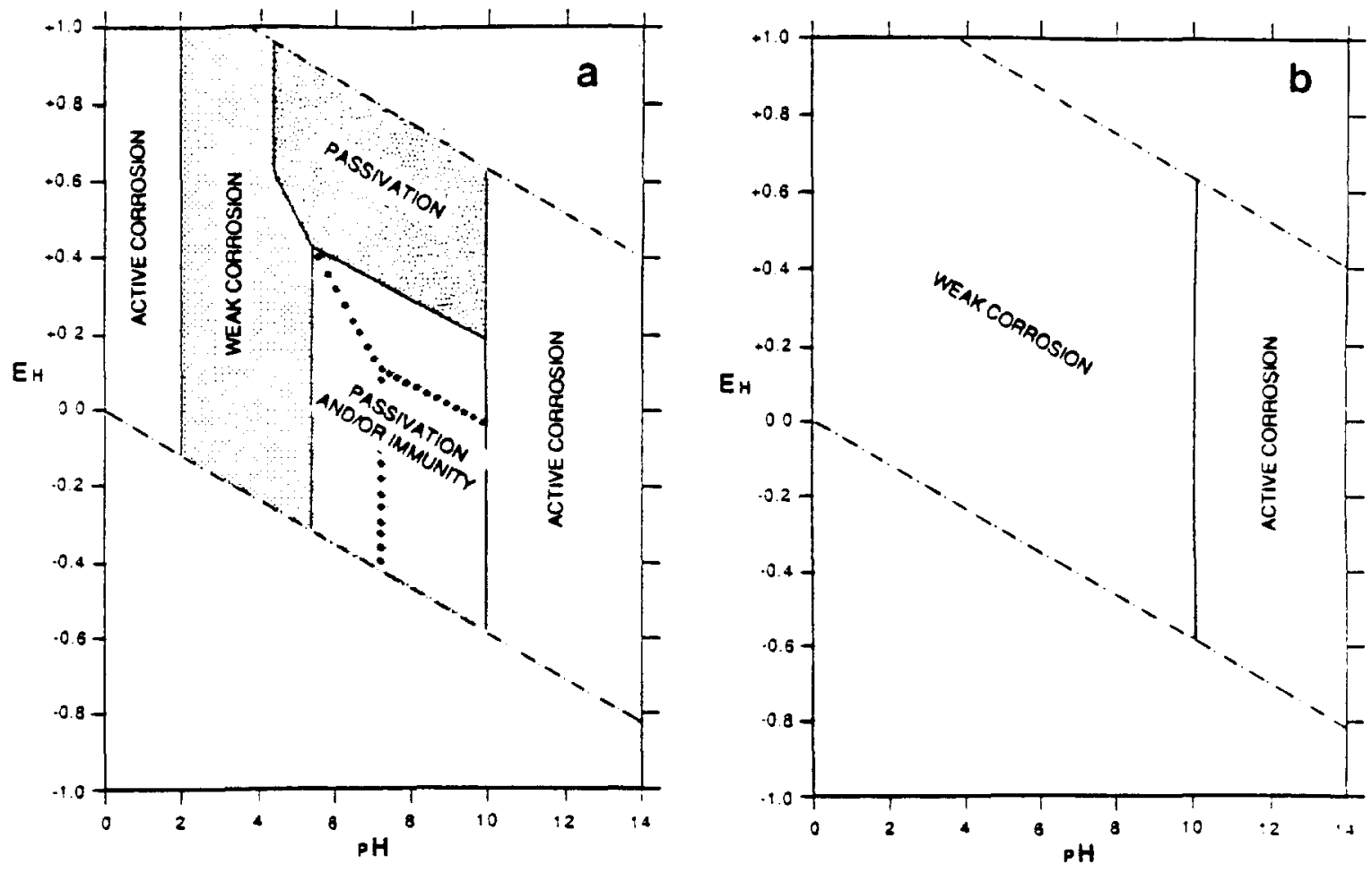

Figure 7a. The Pourbalx diagram for low sillica and borosillicate glasses. Note this diagram can be quantattvely used to predict glass dissolution by superimposing the contours of Figure $6 \mathrm{a}$. b. or $\mathrm{c}$.

7b. Simplifled Pourbaix diagram for high silica glasses. Note this diagram can also be quantatively used to predict glass dissolution as given above.

\section{CONCLUSIONS}

Application of hydration thermodynamics has wide applicability to the prediction of natural, ancient, modern, and nuclear waste glass durability. The predicted durabilities correlate with those observed in nature and glve a means for interpolation of the long-term durabillty of nuclear waste glasses. Hydration thermodynamics can also be used to determine the relative durability of commercial glasses and for archeological applications. The hydration thermodynamic approach was shown to apply to such measures of reaction progress as $\mathrm{Si} . \mathrm{B}$, and $\mathrm{K}$ releases from solution in both short term and long term laboratory tests. The approach was also shown to apply to glass surface "depths of attack" from 2 year and 5 year in-situ burlal tests in Sweden and in the United Kingdom.

Hydration thermodynamics furnishes a quantitative frame of reference to explain how the following parameters affect glass durabllity:

(1) exposed surface area (SA) of the solld

(2) volume (V) of the leaching solution

(3) frequency of replenishing/changing the solution. e.g. time duration $(t)$ of the experiment

(4) temperature (T) of leaching in ${ }^{\circ} \mathrm{C}$

(5) glass composition

Combined with the thermodynamic concepts of Pourbaix diagram construction, the hydration thermodynamic approach has been shown to predict the response of glass to environmental conditions, e.g. solution pH and oxdation potential. 


\section{ACKNOWLEDGEMENTS}

Special thanks are due to Robert Brill of the Corning Museum of Glass for providing the synthetic ancient, chinese, islamic, medieval, mixed alkali. microtektite, and lunar glasses, as well as, the actual ancient museum specimens. Robert Weeks of Vanderbilt University donated the Libyan Desert Glass while John Wosinskd of Corning Glass Works and John O'Keefe of NASA supplied several of the natural tektites. Theodore Fredericks of A\&T Mineral Corporation also generously donated natural tektites, obsidian, and nepheline. Roy Newton of the University of Sheffleld supplied the synthesized medieval window glasses of the European Science Foundation (ESF).

The information contained in this article was developed during the course of work under Contract No. DE-AC09-76SR00001 with the U.S. Department of Energy.

\section{REFERENCES}

1. A. Paul, Chemistry of Glasses, Chapman and Hall, NY (1982).

2. A. Paul. J. Mat, Scl. 12, 2246 (1977).

3. R. J. Charies. J. Appl. Phys. 29. 1549 (1958).

4. R.K. Iler, Colloid Chemistry of Sillca and Silicates, Cornell Univ. Press, Ithaca, NY (1955).

5. J. D. Rimstidt and H. Z. Barnes, Geochem. Cosmochem. Acta. 44, 1683 (1980).

6. R. W. Douglas and T. M. M. El-Shamy, J. Am. Ceram, Soc. 50, 1 (1967).

7. B. Grambow, Glastechnische Berichte 56, 566 (1983).

8. R. M. Wallace and G. G. Wicks, Scientific Basts for Nuclear Waste Management. VI. D. G. Brookins (Ed.) 23 (1983).

9. A. C. Lasaga. "Chemical Kinetics of Water-Rock Interactions", J. Geophys. Res. 89, 4009(1984).

10. J. A. Kittrick. ACS Symposium Sertes 93, 401 (1979).

11. M. Pourbaix, "Atlas of Electrochemical Equilibria in Aqueous Solutions". Eng.Trans. by J.A. Franklln, NACE,Houston, TX,644p (1974).

12. R M. Garrels and C. L. Christ, Solutions, Minerals, and Equilibria Harper and Row, NY 435p. (1965).

13. H. C. Helgeson and F. T. Mackenzle, Deep Sea Res. 17, 877 (1970).

14. J. D. Rimstidt, The Kinetics of Silica-Water Reactions, Unpublished PhD Thesis. The Pennsylvanla State University, 135p (1979).

15. R. G. Newton and A. Paul, Glass Technology. 21, 307 (1980).

16. US Dept. of Energy. Waste Form Selection for SRP Hiah-Level Waste. Report No. DOE/EA-0179 (1982).

17. R C. Ewing. Sct. Basts for Nuclear Waste Mat. _, G. J. McCarthy (Ed.), Plenum Press, NY, 57 (1979).

18. G. Malow and R. C. Ewing . Sct. Basis for Nuclear Waste Mat. III J. G. Moore (Ed.), Plenum Press, NY, 315 (1981).

19. G. Malow, W. Lutze and R. C. Ewing. J. Non-Cryst. Sollds, 67, 305 (1984).

20. M. J. Plodinec, C. M. Jantzen, and G. G. Wicks, Adv, in Ceramics, V.8. G. G. Wicks and W. A. Ross (Eds.), Am. Ceram.Soc., Columbus, OH, 491 (1984).

21. M. J. Plodinec, C. M. Jantzen and G. G. Wicks, Sct. Basis for Nuclear Waste Mat. VIl G. L. McVay (Ed.). North-Holland, NY.755(1984).

22. C. M. Jantzen and M. J. Plodinec, J.Non-Crust. Solids, 67,207 (1984).

23. C. M. Jantzen, Adv, in Ceramics V.20, D. E. Clarke, et. al. (Eds.) Am. Ceram. Soc., Columbus, OH, 703 (1986).

24. C. M. Jantzen, Nuclear Waste Glass Durability: I. Predicting Environmental Response from Thermodynamic (Pourbaix) Diagrams. DP-MS-87-2. J. Am. Ceram. Soc. (in press). 
25. C. M. Jantzen. Pourbalx Diagram for the Prediction of Waste Glass Durability in Geologic Environments, Scl. Basis for Nuclear Waste Mot. XI. M. J. Apted and R.E. Westerman (Eds.). Materials Research Society. Pittsburgh, PA, DP-MS-87-77 (In press).

26. C. M. Jantzen, Stabllity of Radioactive Waste Glasses in Groundwaters Assessed from Hydration Thermodynamics. Sct. Basts for Nuclear Waste Mat..XII, W. Lutze (Ed.) DP-MS-87-76X (in preparation).

27. J. M. Stevels. Progress in the Theory of the Phvsical Properties of Glass. Elsevier, NY (1948).

28. J. M. Stevels, Phillips Tech. Rev, 22, 300 (1960/61).

29. F. J. Pettjohn, J. Geology, 49.610 (1941).

30. F. C. Loughnan, Chemical Weathering of the Sillicate Minerals, Elsevier, NY 141p. (1969).

31. R. G. Newton, J.Glass Studles, 17, 161 (1975).

32. D. G. Howitt, Phys, Chem, Glasses, 22, 29 (1981).

33. C. H. L. Goodman, Glass Technology, 28 [1]. 19 (1987).

34. C. M. Jantzen, Nuclear Waste Glass Durabllity: II. Structural Considerations. $J$. Am. Ceram. Soc, (in preparation).

35. J.E. Mendel (compller). U.S. DOE Report DOE/TIC-1 1400 (1981).

36. N. E. Bibler and C. M. Jantzen, A Product Consistency Durability Test for SRP Nuclear Waste Glass, DP-MS-87-174 (1988).

37. R. G. Newton. Glass Technology. 26[6]. 293 (1985).

38. R. G. Newton, More Results from the Ballidon Glass Burlal Experiment, Glass Technology (in press).

39. C. M. Jantzen and R. G. Newton, Application of Hydration Thermodynamics to the Durability of Medieval Window Glasses (in preparation).

40. G. G. Wicks, B. M. Robnett, and W. D. Rankin, Scl. Basis for Nuclear Waste Mgt. V, W. Lutze (Ed.). Elsevier Publ. Co., New York, 15 (1982).

41. B. Grambow, Adv, in Ceramics, V. 8, G. G. Wicks and W. A. Ross (Eds.), The American Ceramic Society. Columbus, OH, 474 (1984).

42. B. Grambow and D. M. Strachan. Sct. Basis for Nuclear Waste Mgt. VII.

G. L. McVay (Ed.). North-Holland, New York, 623 (1984).

43. D. Cooke and A. Paul, J. Br. Ceram Soc., 77, 104 (1978).

44. M. J. Plodinec, MRS Bulletin, XII 5 l, 61 (1987).

45. V. M. Oversby, Leach Testing of Waste Forms: Interrelationship of ISO and MCC Type Tests, in Workshop on Leaching Mechanisms of Nuclear Waste Forms, PNL-4382, Richland, WA, 97-129 (1982).

46. L. R. Pederson. C. Q. Buckwalter, G. L. McVay and B. L. Riddle, Scl. Basis for Nuclear Waste Mot. VI, D. G. Brookens (Ed.), North Holland . New York. 47 (1983).

47. X. Feng and A. Barkatt. Waste Management '87, Vol.J. R. G. Post and M. E. Wacks (Eds.). 584 (1987).

48. B. Grambow, Scl. Basis for Nuclear Waste Mot. VIIl. C.M. Jantzen, J. A. Stone, and R. C. Ewing (Eds), Materials Research Soctety, Pittsburgh. PA, 15 (1985).

49. C. M. Jantzen. Nuclear Waste Glass Durability: III. The Role of Thermodynamics and Kinetics, J.Am. Ceram. Soc, (in preparation).

50. M. Blumer. Helv. Chim. Acta, 33,1568 (1950).

51. W.C. Krumbein and R.M. Garrels, J. Geology, 60, 1 (1952).

52. C.M. Jantzen and N.E. Bibler Scl. Basis for Nucl Waste Mgt.IX. L.O.Werme (Ed.), Mat. Res. Soc., Pittsburgh, PA, 219 (1986).

53. C.M. Jantzen and G.G. Wicks, Scl. Basis for Nucl. Waste Mgt. VIII, C.M.Jantzen, J. A. Stone, and R. C. Ewing (Eds.). Mat. Res. Soc., Pittsburgh, PA, 29 (1985).

54. P.B. Adams, J. Non-Cryst Sollds, 67,193 (1984).

55. T. M. El Shamy, Phys. Chem. Glasses, 14[1] 1 (1973).

56. L.L. Hench and D.E. Clark. J.Non-Cryst. Sollds. 28, 83 (1978). 